UDK: 005.936.5(043.3)

DOI: https://doi.org/10.24867/07MO02Simeunovic

\title{
UTICAJ PARAMETARA MATRIKSA NA UKLANJANJE BISFENOLA A IZ PROCED- NIH DEPONIJSKIH VODA PRIMENOM FOTOKATALITIČKE DEGRADACIJE
}

\section{THE INFLUENCE OF MATRIX PARAMETERS ON THE REMOVAL OF BISPHENOL A FROM LANDFILL LEACHATE USING PHOTOCATALYTIC DEGRADATION}

\author{
Uroš Simeunović, Mladenka Novaković, Ivana Mihajlović, Maja Petrović, \\ Fakultet tehničkih nauka, Novi Sad
}

\author{
Oblast - INŽENJERSTVO TRETMANA I ZAŠTITA \\ VODA
}

Kratak sadržaj - Bisfenol A predstavlja hormonski disruptor sa potencijalno kancerogenim dejstvom koji se nalazi pretežno u polikarbonatnoj plastici i epoksi smoli. Velika količina otpada sa sadržajem bisfenola A svakodnevno se odlaže na deponije komunalnog otpada. $U$ okviru rada ispitano je uklanjanje poznate koncentracije bisfenola A iz laboratorijski sintetisanog uzorka $i$ realnog uzorka procedne vode. Upoređivanjem rezultata ocenjen je uticaj prirodnog okruženja procedne deponijske vode na efikasnost uklanjanja bisfenola $A$ primenom fotokatalitičke degradacije.

Ključne reči: Bisfenol A, procedna deponijska voda, fotokatalitička degradacija

Abstract - Bisphenol A is an organic component which is predominantly part of polycarbonate plastics and epoxy resins. Polycarbonate plastics are widely used because of their resistance and durability. A large amount of waste containing bisphenol $A$ is disposed at municipal solid waste landfills on a daily basis. The use of bisphenol $A$ is banned in many countries. Bisphenol A is a hormonal disruptor with a potentially carcinogenic effect. The removal of a known concentration of bisphenol $A$ from a laboratory-synthesized sample and a real sample from municipal solid waste landfill was investigated. The influence of the natural environment of leachate on the removal efficiency of bisphenol A using photocatalytic degradation, has been estimated by comparison of the results.

Keywords: Bisphenol A, landfill leachate, photocatalytic degradation

\section{UVOD}

Neadekvatno deponovanje otpada dovodi do kontaminacije svih medijuma životne sredine (vode, vazduha, zemljišta i biote). Voda koja perkolira kroz deponovani otpad, rastvara različite materije koje horizontalnom i vertikalnom migracijom dospevaju i do podzemnih voda [1].

Kompleksnim fizičkim procesima, hemijskim i biohemijskim reakcijama $u$ telu deponije generišu se brojne toksične organske i neorganske materije sa mogućnošću daljih složenih interakcija.

\section{NAPOMENA:}

Ovaj rad proistekao je iz master rada čiji mentor je bila dr Maja Petrović, docent.
Plastifikatori su organski estri koji se dodaju polimerima da bi se unutrašnjom modifikacijom polimernih molekula olakšala obrada i povećala fleksibilnost i izdržljivost krajnjih proizvoda. Koriste se u izradi ambalaže, odeće, boja, lepkova, kozmetike i mnogih drugih proizvoda. Nekoliko plastifikatora je detektovano i u mineralnim, ultra čistim vodama, kao i vodi sa česme, kompostu čvrstog otpada, mulju za prečišćavanje otpadnih voda, deponijama [2].

Bisfenol A $\left(\left(\mathrm{CH}_{3}\right)_{2} \mathrm{C}\left(\mathrm{C}_{6} \mathrm{H}_{4} \mathrm{OH}\right)_{2}\right)$ pripada grupi difenilmetanovih derivata koji se najčešće nalaze u polikarbonatnoj plastici i epoksi smoli. Bisfenol A (BPA) je bezbojna čvrsta supstanca koja se dobro rastvara $u$ organskim rastvaračima, a slabo u vodi. U komercijalnoj upotrebi je od 1957. godine. Potencijalni je endokrini disruptor i često se nalazi u procednim deponijskim vodama. Neke studije Nacionalnog instituta za životnu sredinu u Japanu detektovale su BPA u 5 od 8 uzoraka procedne deponijske vode, a srednja vrednost koncentracija iznosila je 0,35 $\mu \mathrm{g} / \mathrm{L}$. Ipak faktori koji utiču na koncentraciju BPA u procednoj deponijskoj vodi i dalje nisu definisani [3].

Kako su procedne vode veoma opterećene složenim i teško razgradivim neorganskim i organskim jedinjenjima, proces prečišćavanja je vrlo složen i zahtevan postupak. Postrojenja za tretman otpadnih procednih voda podrazumevaju složen tehnološki postupak, a sami pogonski troškovi su vrlo visoki.

Zbog toga se češće primenjuje predtretman procednih voda na lokaciji i nakon toga se vrši ispuštanje $u$ kanalizaciju, a delimično tretirane procedne vode mešaju se sa komunalnim otpadnim vodama i tretiraju na gradskim uređajima za prečišćavanje otpadnih voda [4].

Heterogena fotokataliza primenom poluprovodnika poput cink oksida $(\mathrm{ZnO})$ ili titanijum dioksida $\left(\mathrm{TiO}_{2}\right)$ predstavlja naprednu oksidacionu tehniku koja je bazirana formiranju in situ hidroksilnih radikala koji razgrađuju širokog dijapazon organskih polutanta zbog svoje neselektivne prirode. Cink oksid se može definisati kao adekvatna zamena za tradicionalni titanijum oksid zbog svojih jedinstvenih karakteristika.

U okviru rada procenjivan je uticaj prirodnog matriksa procedne vode deponije komunalnog otpada na efikasnost uklanjanja bisfenola A procesom fotokatalitičke degradacije. 


\section{POREKLO BISFENOLA A U PROCEDNIM VODAMA DEPONIJE}

BPA nije pronađen kao prirodna supstanca u životnoj sredini, njegovo prisustvo je posledica proizvodnje, potrošnje i odlaganja materijala koji ga sadrži. Izvori BPA se mogu klasifikovati kao "pre-konzumacija" (sve aktivnosti vezane za samu proizvodnju plastike) i "postkonzumacija“" (oslobađanje iz odloženog otpada) [5].

BPA se oslobađa u životnu sredinu kroz otpadne vode, ispiranjem sa deponija (hidroliza BPA iz plastike) ili prirodnom razgradnjom polikarbonatne plastike. Najveća koncentracija pronađena je u procednim deponijskim vodama, više od $17 \mathrm{mg} / \mathrm{L}$ [6], a najmanja koncentracija je detektovana u čistim bistrim vodama, i reda je veličine $\mu \mathrm{g} / \mathrm{L}[7]$

Polikarbonatna plastika sa sadržajem bisfenola A nalazi se $\mathrm{u}$ velikom broju proizvoda koji na kraju životnog ciklusa završavaju odloženi na deponije komunalnog otpada, kao plastične flaše za vodu i sokove, flašice i cucle za bebe, plastične kutije za hranu, sportska oprema, medicinska i stomatološka oprema (delovi dijalizatora, inkubatora, oksigenatora, sočiva naočara, zubne ispune). Epoksidne smole se koriste kao unutrašnji zaštitni sloj konzervi/limenki hrane i pića, a pored toga se široko primenjuju i u građevinarstvu. BPA se može spontano izdvojiti iz ambalaže u malim dozama, a grejanje u mikrotalasnim rernama, pranje u mašinama za sudove, povećana kiselost sadržaja konzerve (npr. paradajz) povećava količinu izdvojenog BPA. Bisfenol A se koristi i u proizvodnji sunčanih naočara i kompakt diskova zbog velike otpornosti na toplotu i električnu energiju, međutim grupa naučnika iz francuskog Instituta za agronomska istraživanja je prvi put pokazala da izlaganje ovoj supstanci ima negativne efekte po zdravlje živih organizama [8].

BPA se pod anaerobnim uslovima smatra nerazgradivim i tako negativno utiče na okolinu. Ova supstanca ostaje i nakon degradacije nekih složenijih polimera. Poli BPAkarbonati dobijeni iz bisfenola A i fosgena su nebiodegradabilni. Generalno, ova grupa aromatičnih polikarbonata ima dugo vreme degradacije uglavnom zbog prisustva aromatičnog prstena, koji može da zaštiti susedne etarske veze od hidrolize vodom ili enzimom. Različiti tipovi degradacionih produkata mogu da se dobiju iz ovog polimera u zavisnosti od $\mathrm{pH}$ vrednosti okoline. $\mathrm{Za} \mathrm{pH}>7$ dobijaju se degradacioni produkti kao što su BPA, amonijak i $\mathrm{CO}_{2}$, a $\mathrm{za} \mathrm{pH}<7$ dobijaju se nerazdvojivi poli BPA-karbonat oligomeri [9].

\section{EKSPERIMETALNI DEO}

Za potrebe eksperimentalnog dela rada korišćen je $\mathrm{ZnO}$ kao katalizator, iz razloga što je lako dostupan, netoksičan i vrlo stabilan. Ispitivan je uticaj mase katalizatora $(20,50$ i $80 \mathrm{mg})$, početne koncentracije bisfenola A $(1,5,10$ i 20 $\mathrm{mg} / \mathrm{L})$ i uticaj vremena fotokatalize $(5,10,20,30,40,50$, 60 i 90 minuta) na efikasnost uklanjanja bisfenola $\mathrm{A}$ iz laboratorijski sintetisanog uzorka. Nakon, utvrđivanja efikasnosti procesa fotokatalize na laboratorijski sintetisanom uzorku, ispitana je kinetika procesa uklanjanja bisfenola A iz realnog uzorka procedne vode sa deponije čvrstog komunalnog otpada u Novom Sadu. $\mathrm{pH}$ vrednost realnog uzorka je podešana na 3 pomoću koncentrovane $85 \%$ ortofosforne kiseline kako bi se sprečila disocijacija prisutnog bisfenola $\mathrm{A}$. Podešena $\mathrm{pH}$ vrednost uzorka i uzorci su filtrirani, a zatim je sproveden proces fotokatalize u trajanju od $5,10,20,30,40,50,60$ i 90 minuta.

Uzorci su nakon procesa fotokatalize pripremljeni metodom čvrsto-tečne ekstrakcije (SPE) za analizu na tečnom hromatografu visokih performansi (HPLC). Čvrsto-tečno ekstrakcija je sprovedena pomoću Vakuum Manifold sistema na Oasis HLB ketridžima $(60 \mathrm{mg} / 3 \mathrm{cc})$. Za potrebe kondicioniranja korišćeno je $7 \mathrm{~mL}$ acetonitrila, $5 \mathrm{~mL}$ metanola i $5 \mathrm{~mL}$ destilovane vode, dok je za potrebe eluiranja korišćeno $4 \mathrm{~mL}$ acetonitrila. Nakon eluiranja primenjeno je uparavanje uzorka sa azotom.

HPLC metoda za određivanje koncentracije bisfenola A nakon fotokatalitičkog procesa se sastojala od dve mobilne faze: A - 50\% sirćetne kiseline $(0,1 \%)$ u ultračistoj vodi i $50 \%$ acetonitrila. Izdvajanje analiziranih analita je sprovedeno u izokratskom režimu na reverznoj stacionarnoj fazi Zorbax Extend C18 (karakteristika 150 x 4.6 $\mathrm{mm}$, veličine čestica $5 \mu \mathrm{m})$. Protok mobilnih faza je iznosio $0,8 \mathrm{~mL} / \mathrm{min}$, dok je zapremina injektovanja uzorka iznosila $10 \mu \mathrm{L}$. Maksimalna talasna dužina na kojoj je identifikovan i kvantifikovan bisfenol A je iznosila 276 $\mathrm{nm}$. Retenciono vreme za BPA je iznosilo 4,4 min.

Eksperimentalni deo istraživanja je sproveden $u$ Laboratoriji za monitoring životne i radne sredine, na Departmanu za inženjerstvo zaštite životne sredine i zaštite na radu, na Fakultetu tehničkih nauka.

\section{REZULTATI I DISKUSIJA}

Efikasnost uklanjanja bisfenola A za različite mase fotokatalizatora $\mathrm{ZnO}$ prikazana je na slici 1 .

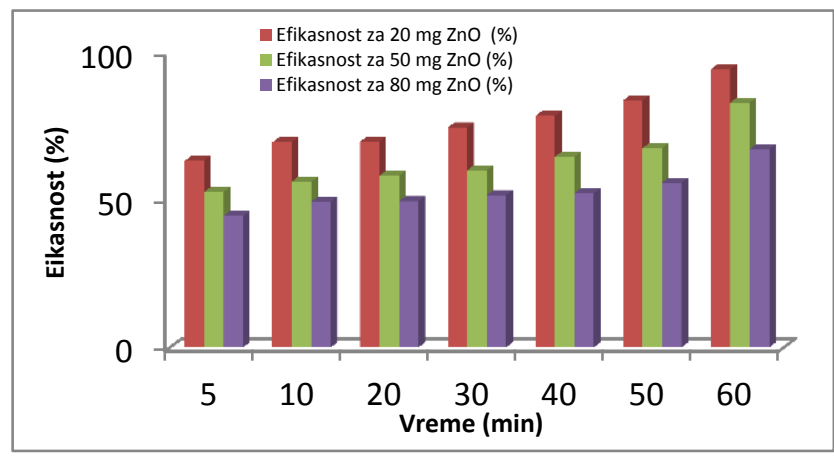

Slika 1. Uticaj mase katalizatora ZnO na uklanjanje bisfenola A

Efikasnost uklanjanja bisfenola A bila je u opsegu od 63,2 do $94,3 \%, 52,7$ do $83,0 \%$ i 44,6 do $67,2 \%$ za mase fotokatalizatora $20,50 \mathrm{i} 80 \mathrm{mg}$, respektivno.

Iako je efikasnost uklanjanja bila najveća za $20 \mathrm{mg} \mathrm{ZnO}$, $\mathrm{u}$ daljim ispitivanjima fotokatalize za realan uzorak korišćena je masa fotokatalizatora od $50 \mathrm{mg}$, jer je realan uzorak heterogena smeša i katalizator ne bi imao relevantnu efikasnost. 
Uticaj početne koncentracije bisfenola A $(1,5,10$ i 20 $\mathrm{mg} / \mathrm{L})$ na fotokatalitički proces je prikazan je na slici 2.

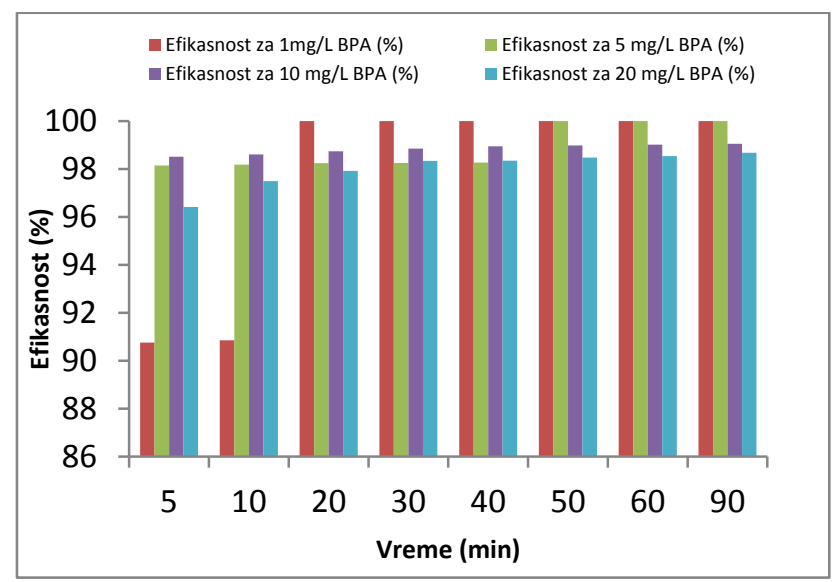

Slika 2. Uticaj početne koncentracije bisfenola A na efikasnost fotokatalize

Iz priloženih podataka može se zaključiti da se sa povećanjem koncentracije bisfenola A, smanjuje efikasnost njegovog uklanjanja fotokatalizom. Za koncentraciju od $1 \mathrm{mg} / \mathrm{L}$ već nakon 20 minuta fotokatalize BPA je skroz uklonjen, dok se koncentracija od $20 \mathrm{mg} / \mathrm{L}$ nakon 20 minuta uklonila sa efikasnošću 97,92 \%, a nakon čak 90 minuta bisfenola A je i dalje bilo u uzorku $(98,68 \%$ efikasnost).

Efikasnost uklanjanja BPA iz realnog uzorka u zavisnosti od vremena trajanja fotokatalize prikazana je u Tabeli 1 .

Tabela 1. Efikasnost uklanjanja BPA iz realnog uzorka $u$ zavisnosti od vremena trajanja fotokatalize

\begin{tabular}{|c|c|c|}
\hline Vreme (min) & $\begin{array}{c}\text { Koncentracija } \\
(\mathbf{m g} / \mathbf{L})\end{array}$ & Efikasnost (\%) \\
\hline 5 & 0,0681 & 2,78 \\
\hline 10 & 0,0673 & 3,80 \\
\hline 20 & 0,0656 & 6,28 \\
\hline 30 & 0,0633 & 9,60 \\
\hline 40 & 0,0547 & 21,85 \\
\hline 50 & 0,0533 & 23,90 \\
\hline 60 & 0,0507 & 27,52 \\
\hline 90 & 0,0482 & 31,14 \\
\hline
\end{tabular}

Efikasnost uklanjanja BPA iz realnog uzorka niska je čak i nakon 90 minuta fotokatalize (Tabela 1) što ukazuje na značajan uticaj matriksa na efikasnost uklanjanja bisfenola postupkom fotokatalitičke degradacije. Isti postupak uklanjanja bisfenola A iz laboratorijskog uzorka, pri različitim koncentracijama bisfenola A pokazivao je i do 3 puta veću efikasnost uklanjanja za sve vremenske intervale fotokatalize.

\section{ZAKLJUČAK}

Neadekvatno deponovanje otpada dovodi do kontaminacije svih medijuma životne sredine (vode, vazduha, zemljišta i biote). Jedan od najvećih problema koji proističu iz nekontrolisanog i neorganizovanog odlaganja otpada na smetlišta i deponije jeste zagađenje voda. Voda koja se infiltrira u telo deponije vodi poreklo od vlage sadržane u otpadu, atmosferskih padavina, infiltrirane vode sa okolnih zemljišta, vode nastale kao proizvod hemijskih reakcija u deponovanom materijalu i recirkulisane procedne vode. Procedna voda predstavlja složenu, heterogenu smešu promenjivog sastava, koja se sastoji od različitih organskih i neorganskih jedinjenja i mikroorganizama.

Bisfenol A je organska supstanca često prisutna $\mathrm{u}$ procednoj vodi sa deponija kao posledica odlaganja različitih proizvoda široke potrošnje.

Eksperimentalni deo rada zasnovan je na uklanjanju bisfenola A procesom fotokatalitičke degradacije. Cilj rada bio je da se uporedi efikasnost uklanjanja poznate koncentracije bisfenola A iz laboratorijskog uzorka sa efikasnošću uklanjanja iz realnog uzorka u cilju utvrđivanja uticaja matriksa realnog uzorka na efikasnost uklanjanja.

Za potrebe eksperimentalnog dela rada korišćen je $\mathrm{ZnO}$ kao katalizator, iz razloga što je lako dostupan, netoksičan i vrlo stabilan.

$\mathrm{Na}$ osnovu dobijenih rezultata može se zaključiti da prirodni matriks procedne deponijske vode utiče na efikasnost uklanjanja bisfenola A. Efikasnost uklanjanja je i nakon 90 minuta fotokatalitičke degradacije iznosila samo $31,14 \%$. Joni prisutni u realnom uzorku procedne vode se mogu ponašati kao inhibitori fotokatalitičkog procesa čime se smanjuje efikasnost razgradnje bisfenola A, kao i prisutnost drugih organskih polutanata.

Predlog daljih istraživanja bi bila analiza fotokatalitičke degradacije bisfenola $\mathrm{A}$ u realnom uzorku primenom dužeg vremena zračenja, veće mase fotokatalizatora i nakon primarnog i sekundarnog tretmana.

Buduća istraživanja trebalo bi fokusirati na ispitivanje najboljih dostupnih tehnologija tretmana realnih uzoraka procedne deponijske vode, kao i na ispitivanje uticaja pojedinačnih hemijskih parametara na efikasnost prečišćavanja.

\section{ZAHVALNICA}

Autori se zahvaljuju projektu Gradske uprave za zaštitu životne sredine grada Novog Sada, u okviru projekta Procena rizika ekostatusa životne sredine Novog Sada u okolini deponije komunalnog otpada, realizovanog $\mathrm{u}$ periodu 2018-2019. godine i projektu Pokrajinskog Sekretarijata AP Vojvodine pod nazivom Sinteza i primena novih nanostrukturnih materijala za razgradnju organskih polutanata iz procednih voda komunalnih deponija u Vojvodini, realizovanog od 2016-2020.godine, broj: 142-451-2129/2019-01/02.

\section{LITERATURA}

[1] M. Đogo, J.Radonić, I. Mihajlovic, B. Obrovski, D. Ubavin, M. Turk Sekulić, M. Vojinović Miloradov, "Selection of optimal parameters for future research monitoring programmes on MSW landfill in Novi Sad, Serbia", Fresenius Environmental Bulletin, Vol.26(7), pp. 4867-4875, 2017. 
[2] N.C. Vieceli, E.R. Lovatel, E.M. Cardoso, I.N. Filho, "Study of bisphenol A in sanitary landfill soil", Sustainable Chemistry, Vol.154, pp. 225-231, 2011.

[3] T. Yamamoto, A. Yasuhara, H. Shiraishi, O. Nakasugi, "Bisphenol A in hazardous waste landfill leachates", Chemosphere, Vol.42, pp. 415-418, 2001.

[4] M. Klašnja, "Obezbeđivanje kvaliteta vode u pripremi vode i prečišćavanju otpadnih voda" Poglavlje u monografiji, Monografija „Kontrola kvaliteta voda $u$ okviru upravljanja kvalitetom“ Prirodno-matematički fakultet, Institut za hemiju, Novi Sad, str. 62-76, 2000.

[5] J. Corrales, L.A. Kristofco, W. Baylor Steele, B.S. Yates, C.S. Breed, E.S. Williams, B.W. Brooks,“ Global Assessment of Bisphenol $A$ in the Environment: Review and Analysis of Its Occurrence and Bioaccumulation”, Dose-Response, Vol, pp. 1-29, 2015.

[6] S. Flint, T. Markle, S. Thompson, E. Wallace, "Bisphenol A exposure, effects, and policy: A wildlife perspective", Journal of Environmental Management, Vol. 104, pp. 19-34, 2012.

[7] D.A. Crain, M. Eriksen, T. Iguchi, S. Jobling, H. Laufer H, G.A. LeBlanc, L.J.Jr. Guillette, "An ecological assessment of bisphenol-A: evidence from comparative biology", Reproductive Toxicology, Vol.24. pp. 225-239, 2007.

[8] L. Xiangli, L. Li, Z. Shichun, L. Chongyu, L. Tiangang, "Determination of Bisphenol A in Landfill Leachate by Solid Phase Microextraction with Headspace Derivatization and Gas ChromatographyMass Spectrophotometry", Chinese Journal of Analytical Chemistry, Vol.34(3), pp. 325-328, 2006.

[9] A. Aziz, P. Agamuthu, S.H. Fauziah, "Removal of bisphenol A and 2,4-Di-tert-butylphenol from landfill leachate using plant-based coagulant", Waste Management \& Research, Vol. 36(10), pp. 975-984, 2018.

\section{Kratka biografija:}

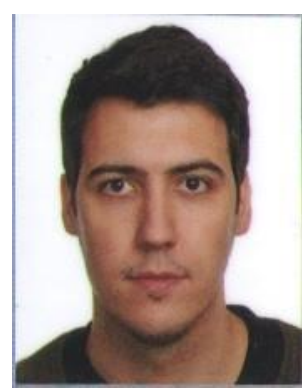

Uroš Simeunović rođen je u Beogradu. Diplomirao je na Biološkom fakultetu u Beogradu, smer ekologija. Završna godina master studija Fakulteta tehničkih nauka u Novom Sadu, smer Inženjerstvo tretmana i zaštita voda. 